7th International Symposium on Superalloy 718 and Derivatives Edited by: E.A. Ott, J.R. Groh, A. Banik, I. Dempster, T.P. Gabb, R. Helmink, X. Liu, A. Mitchell, G.P. Sjöberg, and A. Wusatowska-Sarnek TMS (The Minerals, Metals \& Materials Society), 2010

\title{
Flowforming of a Nickel Based Superalloy
}

\author{
Shawn Rhodes ${ }^{1}$, Juan Valencia ${ }^{1}$, John Ryan ${ }^{1}$, Steven Stawarz ${ }^{1}$, Christopher Humiston ${ }^{2}$ \\ ${ }^{1}$ Concurrent Technologies Corporation, \\ 100 CTC Drive, Johnstown PA, 15904, USA \\ ${ }^{2}$ ARDEC, Watervliet Arsenal, \\ 1 Buffington St., Watervliet, NY 12189, USA
}

Keywords: Flowforming, Process Modeling

\begin{abstract}
Flowforming is a relatively new metalworking technology that has been applied to successfully cold formed triple melt Inconel 718. The large plastic deformations during flowforming have the benefit of refining the materials microstructure. In the present work, computer simulation, mechanical testing and materials characterization have been conducted to develop a failure/damage model to support the cold forming behavior of an Inconel alloy. Results have enabled the prediction of the conditions for material failure during flowforming operations. In addition, the numerical model also provides information as to the optimum preform and roller geometry, feed rate, and setup parameters in accordance with the desired product end state. The numerical process model in conjunction with proper characterization of the mechanical properties have been useful to substantially reduce the trial and error methods used in flowforming operations.
\end{abstract}

\section{Introduction}

The National Defense Center for Environmental Excellent (NDCEE) is working with Benét Laboratories, the U.S. Army Research and Development Command (RDECOM), Watervliet Arsenal (WVA), and the U.S. Army Tank and Automotive Command (TACOM) to develop a cost-effective solution for manufacturing a new component that will use a nickel based alloy and an innovative manufacturing method-flowforming. The flowformed alloy tubes will reduce the overall weight of the assembly by $10 \%$ and increase its strength, both critical issues for the warfighter.

Flowforming is a manufacturing technique that is ideally suited to replace traditional forging and machining for production of tubular components. In flowforming, a short and thick-walled hollow cylinder preform is fit to a mandrel with the same diameter as the product. Circumferential rollers rotate axially along the preform, cold working it and making it thinner and longer. The process is more economical than drilling a blind inner hole and machining the full outer wall length of an initial rough forging - the process that is used now. Flowforming produces a highly uniform, round, and smooth surface finish. Additionally, the process reduces the cost of manufacturing tubular components by an estimated $90 \%$.

Flowforming is a process that requires large material deformation. Predicting that deformation is difficult; the standard approach is trial and error production on the factory floor, which takes time and consumes resources. The NDCEE team is developing a process modeling and simulation tool in Abaqus ${ }^{\mathrm{TM}}$ to optimize start-up production of flowformed components. Other 
objectives include performing and documenting material characterization; validating the process model so that it can simulate process failures.

\section{Technical Approach}

The first step in developing the model was to characterize the alloy used in the tube production to establish whether heat treatment was required to condition the microstructure for cold formability and to establish the range of strain over which the material can be successfully formed. Characterization also provides the data required for the numerical modeling to predict incipient material failures and to avoid them.

\section{Microstructural Inspection - As Received Material Triple melt Inconel 718 billet}

Macrostructure The macrostructure across the radial direction of the alloy 718 billet was first examined. The macrostructure clearly revealed the forging flow lines that are aligned in a parallel direction of the longitudinal axis of the billet. Also, closer examination of the macrostructure indicated that the forging flow lines are much coarser at the center and gradually become finer towards the surface of the billet. The much coarser flow lines at the center of the billet can be attributed to high macro and microsegregation of the cast billet that persisted even after forging. The macrostructural pattern developed during forging is typical of products that have been thermomechanically processed. Further analysis indicated that cracks, coarse inclusions or coarse segregates such as freckles were not present in the macrostructure.

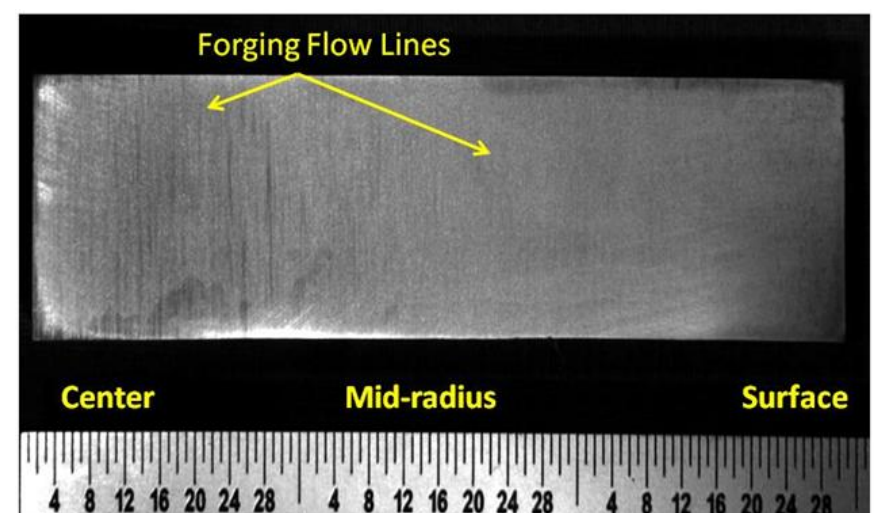

Figure 1. Optical view of the macrostructure across the radial direction of alloy 718 billet

Microstructure The light optical microstructures (LOM) in the transverse and longitudinal directions across the radius of the as-forged billet were also examined. Significant variations in the grain size were observed as shown in Figure 2. The very coarse grain size at the center is approximately five times larger than the grain size towards the surface of the billet. 


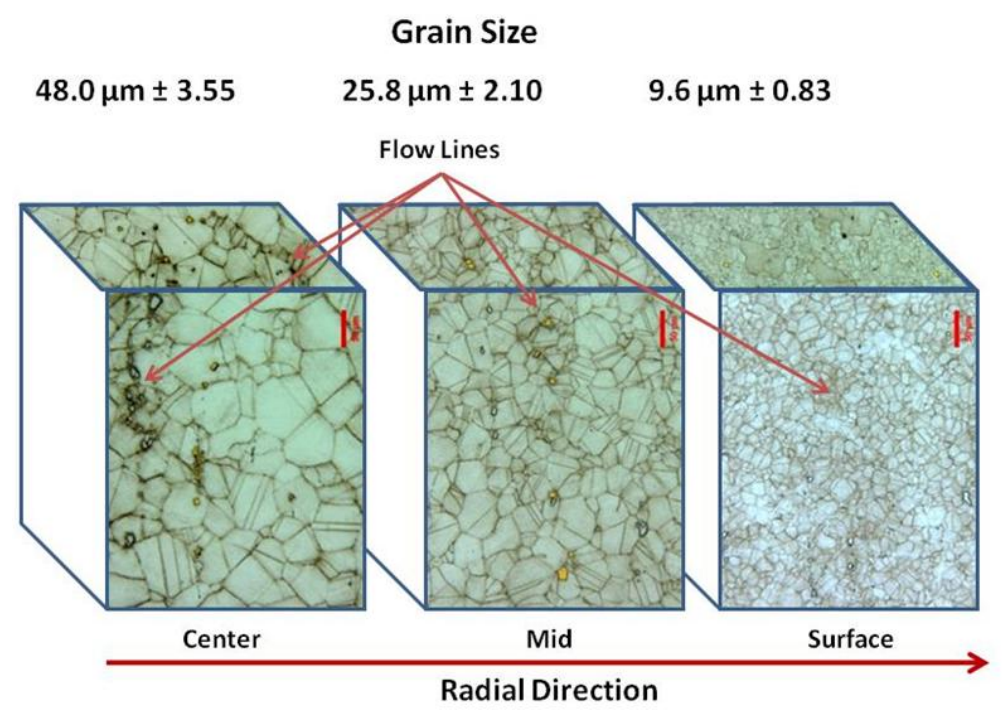

Figure 2. LOM of the forged billet showing the variation in grain size in the radial direction of the alloy 718 in the as-received condition.

The variation in grain size can be attributed to the coarser solidification microstructure at the center of the billet and to the forging process. This microstructure suggests that the center of the billet was not heavily deformed by the forging process. Instead, the exterior of the billet received most of the mechanical work and hence a finer grain size was produced. While at the center of the billet, the grains received less mechanical work and also had more time at temperature for grain growth. Figure 2 also shows the grain size distribution and also shows that the variation (large standard deviation) in grain size was more pronounced at the center of the billet. Further analysis of the microstructures also indicated that the grains have equiaxed morphology. In addition, the presence of coarse phases that are the cause of the flow lines is readily visible.

Further analysis of the microstructure at locations closer to the surface region of the billet showed that the gamma grain size is non-uniform. Instead, a duplex microstructure was identified. Gamma grains as large as $150 \mu \mathrm{m}$ were observed at these locations of the billet. The main implication of having a duplex microstructure is the relatively non-uniformity in mechanical properties. This grain size anomaly could also cause non-uniformity in the cold formability of Alloy 718.

\section{$\underline{\text { High Temperature Heat Treatment }}$}

The main objective of this task was to evaluate the effects of high temperature (above the $\delta$ solvus) heat treatment on the microstructure of Inconel 718 forged billet when cooled at various cooling rates. The evaluation will aid in the selection of heat treatment parameters that could be necessary to condition the microstructure of alloy 718 to attain suitable mechanical properties for flowforming processing operations. In this case the heat treatments were conducted at 1850 ${ }^{\circ} \mathrm{F} / 15 \mathrm{~min}$ and $1900{ }^{\circ} \mathrm{F} / 15$ and cooled at different rates. Qualitatively, the slow cooling was achieved by burying the samples in vermiculate. Air cooling and water quench were used for moderate and fast cooling rates, respectively. 
LOM of the heat treated samples indicated that the material heat treated at $1850{ }^{\circ} \mathrm{F}$ had practically no change in the grain size with respect to the as received material. However, at 1900 ${ }^{\circ} \mathrm{F}$ a rapid increase in grain growth in a very short period of time was observed. Table 1 shows the effect of the heat treatment temperature on the grain size of the samples that were air cooled. These observations clearly indicate that current material without the presence of $\delta$-phase $\left(\mathrm{Ni}_{3} \mathrm{Nb}\right)$ undergoes a rapid grain growth when heat treated above $1850^{\circ} \mathrm{F}(\delta$-solvus 1875 $\left.1890^{\circ} \mathrm{F}[1]\right)$.

Further observations of the microstructures clearly indicate that the rate of cooling had an effect on the amount of precipitation of the heat treated material at $1850{ }^{\circ} \mathrm{F}$ but practically none in the case of material exposed at $1900^{\circ} \mathrm{F}$. The slow cooled and moderate cooled material had a larger amount of precipitates at the grain boundaries than the water quench material. Also, it was observed that the elevated temperatures had no effect on the nitride and carbides present in the microstructure. This is primarily due to the fact that the nitrides are formed in the liquid state and are very stable compounds and there was not sufficient time at temperature to get the carbides in solid solution.

Table 1. Effect of Elevated Temperature Heat Treatment on the Grain Size of Alloy 718 Forged Billet

\begin{tabular}{|c|c|c|c||}
\hline \multirow{2}{*}{ Condition } & \multicolumn{3}{|c||}{ Location, Grain Size in $\mu \mathrm{m} /($ ASTM No.) } \\
\cline { 2 - 4 } & Center & Mid-Radius & Surface \\
\hline As-Forged & $48.0 \pm 3.55 /(5.5)$ & $25.8 \pm 2.10 /(7.3)$ & $9.6 \pm 0.83 /(10.1)$ \\
\hline Heat Treated & $44.2 \pm 4.02 /(5.7)$ & $24.1 \pm 1.6(7.5)$ & $10.6 \pm 0.46 /(9.8)$ \\
\hline $1850^{\circ} \mathrm{F} / 15 \mathrm{~min} . /$ Air Cooled & $82.9 \pm 12.0 /(3.9)$ & $64.5 \pm 6.4 /(4.6)$ & $63.4 \pm 6.6 /(4.7)$ \\
\hline $1900^{\circ} \mathrm{F} / 15 \mathrm{~min} . /$ Air Cooled & $82.6 \pm$ \\
\hline
\end{tabular}

Low Temperature Heat Treatment

Further heat treatment work at temperatures well below the $\delta$-solvus was conducted with the objective to identify a suitable microstructure that could produce a material with high ductility and lower yield strength for further forming operations. The heat treatments were conducted at $700{ }^{\circ} \mathrm{F}, 800^{\circ} \mathrm{F}$ and $1000^{\circ} \mathrm{F}$ for 30,60 and 100 minutes and air cooled. Table 4 shows the various heat treatments used in this work. .

Microstructure Analysis of the microstructures from these heat treatments were relatively uniform at the center and at mid-radius regions of the billet. However, very large and non uniform gamma grains (duplex grain size) are observed at regions of about 0.5 -inch from the surface (between the surface and mid-radius of the billet). Figure 3 shows an example of the resulting microstructures from the 700,800 and $1000 \mathrm{~F} / 100 \mathrm{~min}$./air cooled heat treatments. A further analysis of the heat treated microstructures indicates that time and temperature during heat treatment did not have any effect on the grain size. 

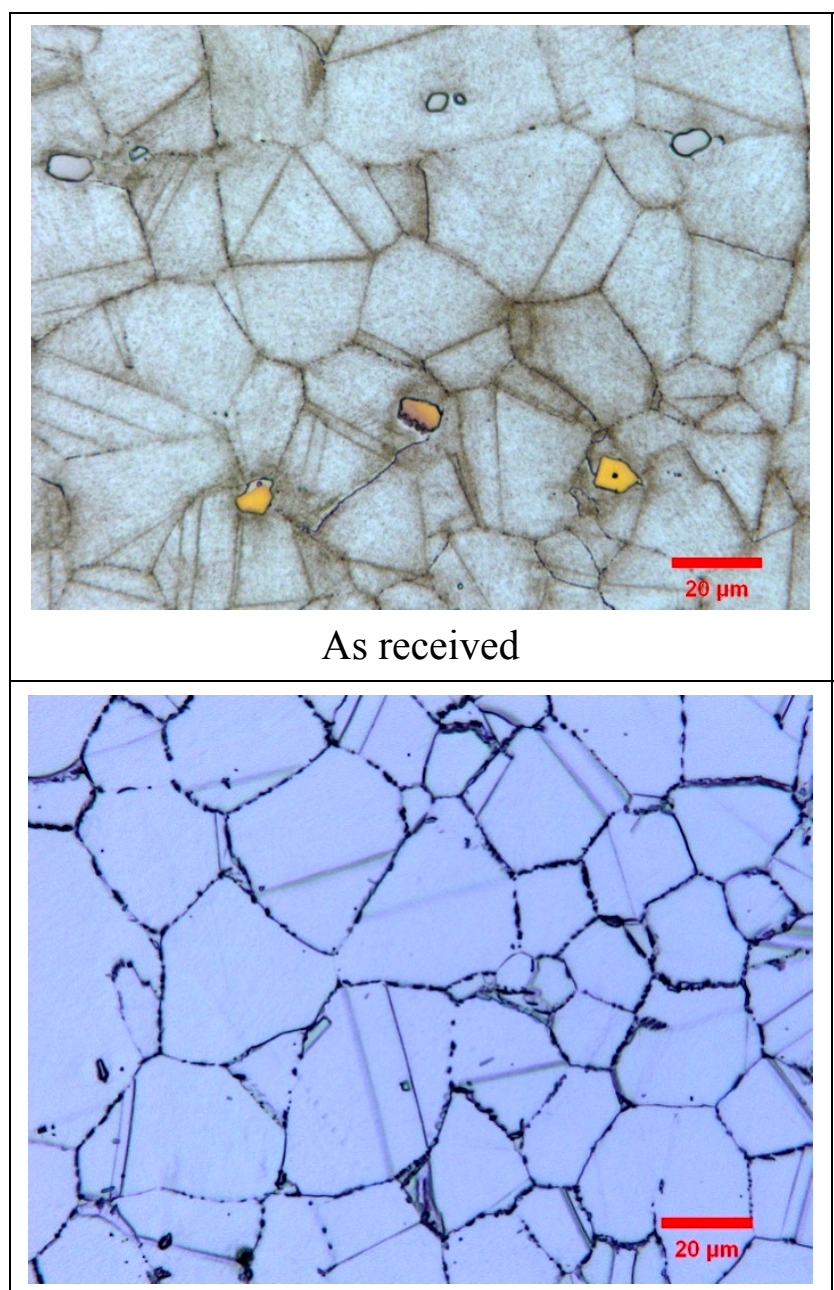

$1850^{\circ} \mathrm{F} / 15 \mathrm{~min}$.

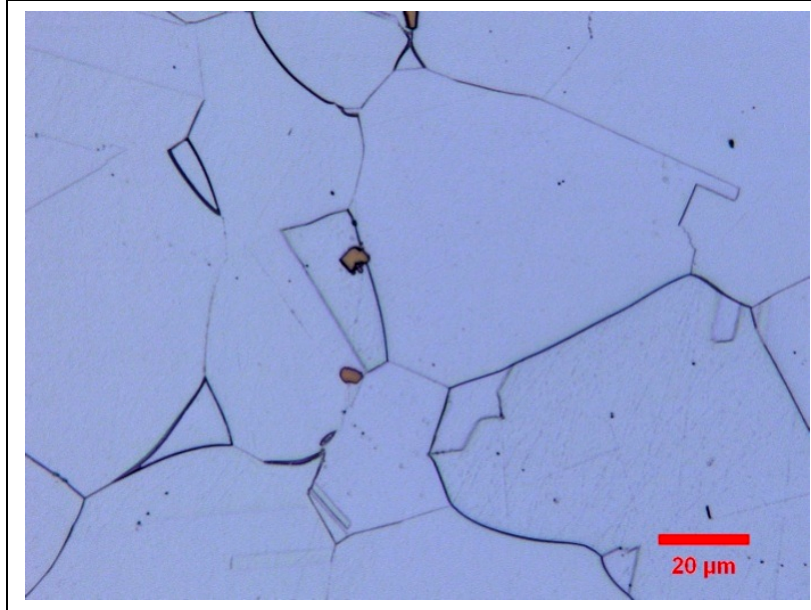

$1900^{\circ} \mathrm{F} / 15 \mathrm{~min}$.

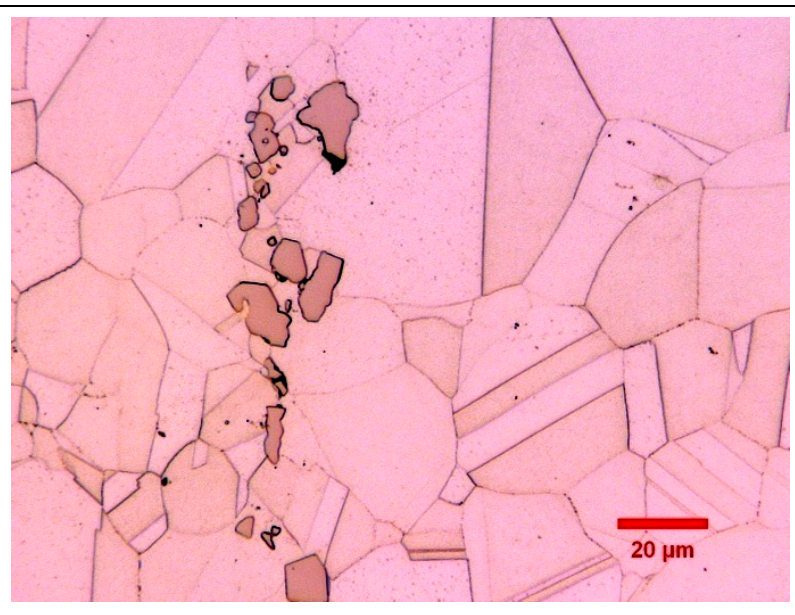

$700^{\circ} \mathrm{F} / 100 \mathrm{~min}$

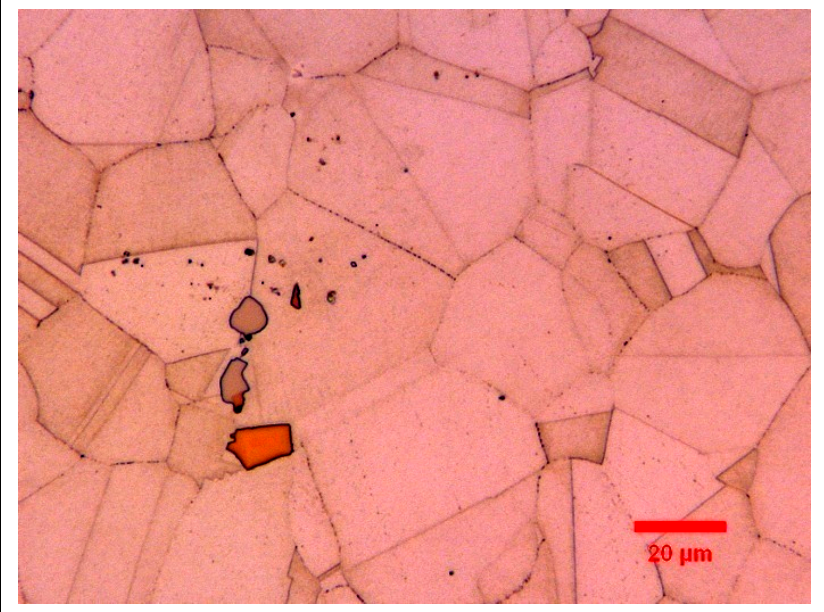

$800{ }^{\circ} \mathrm{F} / 100 \mathrm{~min}$

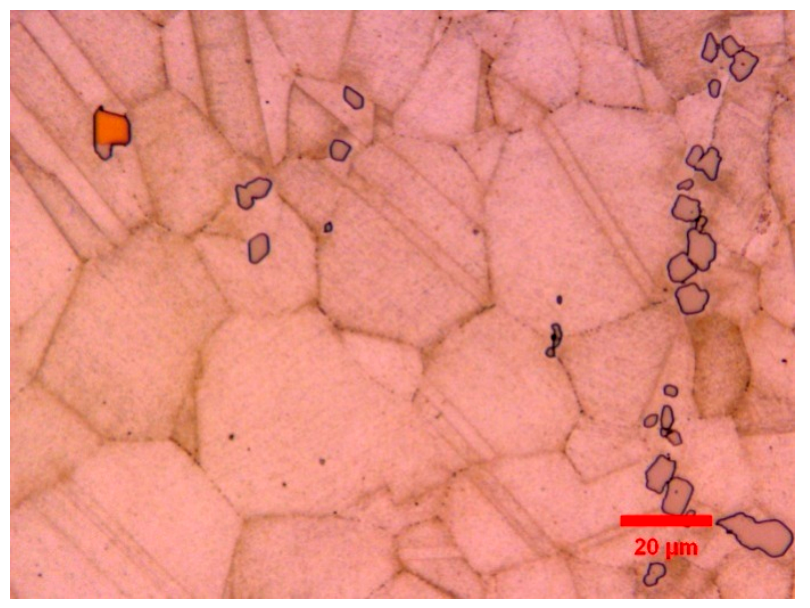

$1000^{\circ} \mathrm{F} / 100 \mathrm{~min}$

Figure 3. Light Optical Microstructures of the Forged Billet from the Middle Region in the Radial Direction of the Alloy 718 Forged Billet in the As-received and heat Treated Conditions

Additional observations of the microstructure indicate that the low temperature heat treatment did not produce any change on the secondary phases at the microscopic optical level. Figure 3 shows an example of the appearance of the optical microstructures of the middle region of the 
billet after heat treatment at the various temperatures and air cooled. For comparison, Figure 3 also shows the microstructures of the as-received and after heat treatment at $1850{ }^{\circ} \mathrm{F} / 15 \mathrm{~min}$ and $1900{ }^{\circ} \mathrm{F} / 15 \mathrm{~min}$ and air cooled. The microstructures of the heat treated material in the 700 to $1000{ }^{\circ} \mathrm{F}$ range consist of a relatively small amount of nitrides and carbides. Note that these second phases were not affected in this temperature range. However, most of the carbides were dissolved at the higher temperatures. As indicated earlier the nitrides are formed at high temperature and were not dissolved by any of the heat treatments used in this work.

Detailed observation of the microstructure also indicated that there is the presence of a relatively small amount of very fine $\delta$-phase at the grain boundaries of the heat treated material. This is also consistent with the microstructure of the as received material. Also, for comparison, the $1850{ }^{\circ} \mathrm{F} / 15 \mathrm{~min} / \mathrm{AC}$ heat treated material shown in Figure 3 shows the larger proportion of a $\delta$ phase. This phase is fully dissolved at $1900^{\circ} \mathrm{F}$ and immediately grain growth follows. This indicates that the $\delta$-phase solvus temperature for this material is approximately $1850{ }^{\circ} \mathrm{F}-1885$ ${ }^{\circ} \mathrm{F}$. This is in good agreement with the $1875-1890{ }^{\circ} \mathrm{F}$ reported in the literature [1]. Detailed microstructure and the second phase precipitates of the heat treated or as-received materials was not possible, since light optical microscopy is not able to resolve the very fine $\gamma^{\prime \prime}\left(\mathrm{Ni}_{3} \mathrm{Nb}\right)$ and $\gamma^{\prime}$ $\left(\mathrm{Ni}_{3}(\mathrm{Al}, \mathrm{Ti})\right)$ intermetallic precipitates in the fcc $\gamma-\mathrm{Ni}$ matrix.

Tensile Properties. The tensile testing of the heat treated samples was only conducted on the samples heat treated exposed to 100 minutes at the various temperatures. The tensile testing was conducted at room temperature as per ASTM E8 standard. Because material limitations sub-size tensile specimens (0.16-inch diameter) were machined in the radial direction from each heat treated sample. The 0.64-inch gage length of the specimens was located about the mid radius of the billet. Table 2 shows average tensile results. In addition, the average tensile properties of the as-received and high temperature treated materials are also shown in the table for comparison. The yield strength of the samples heat treated in the temperature range of $700-800{ }^{\circ} \mathrm{F}$ is slightly lower than that of the as-received material and their elongation is comparable to that of the asreceived material. This indicates that the heat treatment at $700-800^{\circ} \mathrm{F}$ does not have any effect in the tensile properties. A slight increase in the yield strength was observed at $1000{ }^{\circ} \mathrm{F}$, but a significant increase of approximately $32 \%$ in the tensile elongation over the as-received material was observed at this temperature. The slight increase in yield strength and to some degree tensile ductility at $1000{ }^{\circ} \mathrm{F}$ may be attributed to the initial formation of fine the face-centered cubic $\gamma^{\prime}\left(\mathrm{Ni}_{3}(\mathrm{Ti}, \mathrm{Al}, \mathrm{Nb})\right.$ precipitates at 100 minutes of exposure [2]. The increase in tensile ductility and the uniform deformation is beneficial for the cold formability of this material.

The lowest tensile and yield strength and the highest ductility were achieved when heat treating at $1900{ }^{\circ} \mathrm{F}$ for 15 minutes and air cool. However, damage in the microstructure was observed, since, in case the grain size increased from approximately $26 \mu \mathrm{m}$ to $65 \mu \mathrm{m}$ (ASTM 7.3 to 4.6).

The heat treatment at $1850{ }^{\circ} \mathrm{F}$ for 15 minutes and air cool also produced lower tensile (129.5 ksi) and lower yield strength $(70.8 \mathrm{ksi})$ than those of the as received material. In addition, this heat treatment increased the elongation and reduction of area by approximately $68 \%$ and $28 \%$, respectively, over those of the as received material. This combination of properties can be attributed to the dissolution of the very fine carbides, $\gamma^{\prime \prime}\left(\mathrm{Ni}_{3} \mathrm{Nb}\right)$ and $\gamma^{\prime}\left(\mathrm{Ni}_{3}(\mathrm{Al}, \mathrm{Ti})\right)$ intermetallic precipitates in the fcc $\gamma$-Ni matrix. Also, grain growth was not observed with this heat treatment. This is primarily due to the presence of relatively fine $\delta$-phase precipitates at the grain boundaries that prevented grain growth. 
In general this work indicates that forming Alloy 718 in the temperature range of 75 to $800{ }^{\circ} \mathrm{F}$ will not have any effect on the formability behavior of the alloy. While only a marginal improvement in formability could be achieved after heat treatment at $1000^{\circ} \mathrm{F}$. From this study it is reasonable to assume that good formability of the forged Alloy 718 could be achieved after heat treatment just below the $\delta$-phase solvus $\left(1850^{\circ} \mathrm{F}-1885^{\circ} \mathrm{F}\right)$ temperature.

Table 2. Room Temperature Average Tensile Properties of Alloy 718 Forged Billet After Heat Treatment at Various Temperatures and Air Cooled

\begin{tabular}{|c|c|c|c|c|}
\hline $\begin{array}{l}\text { Heat Treatment } \\
\text { Condition }\end{array}$ & $\begin{array}{l}\text { Ultimate Tensile } \\
\text { Strength } \\
(\mathrm{ksi})\end{array}$ & $\begin{array}{l}0.2 \% \text { Offset } \\
\text { Yield Strength } \\
\quad(\mathrm{ksi})\end{array}$ & $\begin{array}{l}\text { Elongation } \\
\text { Increase } \\
\quad(\%)\end{array}$ & $\begin{array}{l}\text { Reduction } \\
\text { of Area } \\
(\%)\end{array}$ \\
\hline As Received ${ }^{1 /}$ & 177.8 & 145.0 & 26.0 & 41.7 \\
\hline & & & & \\
\hline & & & & \\
\hline $700 \mathrm{~F} / 100 \mathrm{~min}^{2 /}$ & 179.59 & 141.54 & 27.34 & 41.91 \\
\hline & & & & \\
\hline $800 \mathrm{~F} / 100 \mathrm{~min}^{2 /}$ & 171.40 & 141.91 & 26.56 & 38.90 \\
\hline & & & & \\
\hline $1000 \mathrm{~F} / 100 \mathrm{~min}^{2 /}$ & 181.47 & 147.91 & 34.38 & 43.14 \\
\hline & & & & \\
\hline $1850 \mathrm{~F} / 15 \mathrm{~min}^{2 /}$ & 129.52 & 70.79 & 43.75 & 53.51 \\
\hline & & & & \\
\hline $1900 \mathrm{~F} / 15 \mathrm{~min}{ }^{2 /}$ & 115.98 & 48.52 & 68.75 & 63.54 \\
\hline \multicolumn{5}{|c|}{$\begin{array}{l}\text { Notes: } \\
{ }^{1 /} \text { Standard } 0.5 \text {-inch diameter ASTM E } 8 \text { Samples } \\
{ }^{2 /} \text { Subsized round samples } 0.16 \text {-inch diameter per ASTM E8. } \\
\text { AC: Forced Air cool }\end{array}$} \\
\hline
\end{tabular}

\section{Flow Stress Characterization}

Flow stress characterization was conducted at higher temperatures, as well as at room temperature, to determine if higher temperatures would show improved properties for flowforming. Flow stress test data was incorporated into a model of the test specimen. Necking and failure behavior of the test specimen was then compared to the model results with good agreement.

A pure shear (torsion) specimen was also created and tested to develop a flow stress curve that captures the material's shear behavior. The test apparatus fixed one end of the specimen while applying a moment to the other. During the test, the free end of the specimen was unconstrained axially. The specimen was designed to achieve approximately two complete revolutions before fracture. Figure 4 compares the tensile and shear flow stress curves for Inconel 718. 


\section{Shear vs. Tensile Flow Stress \\ Inconel 718}

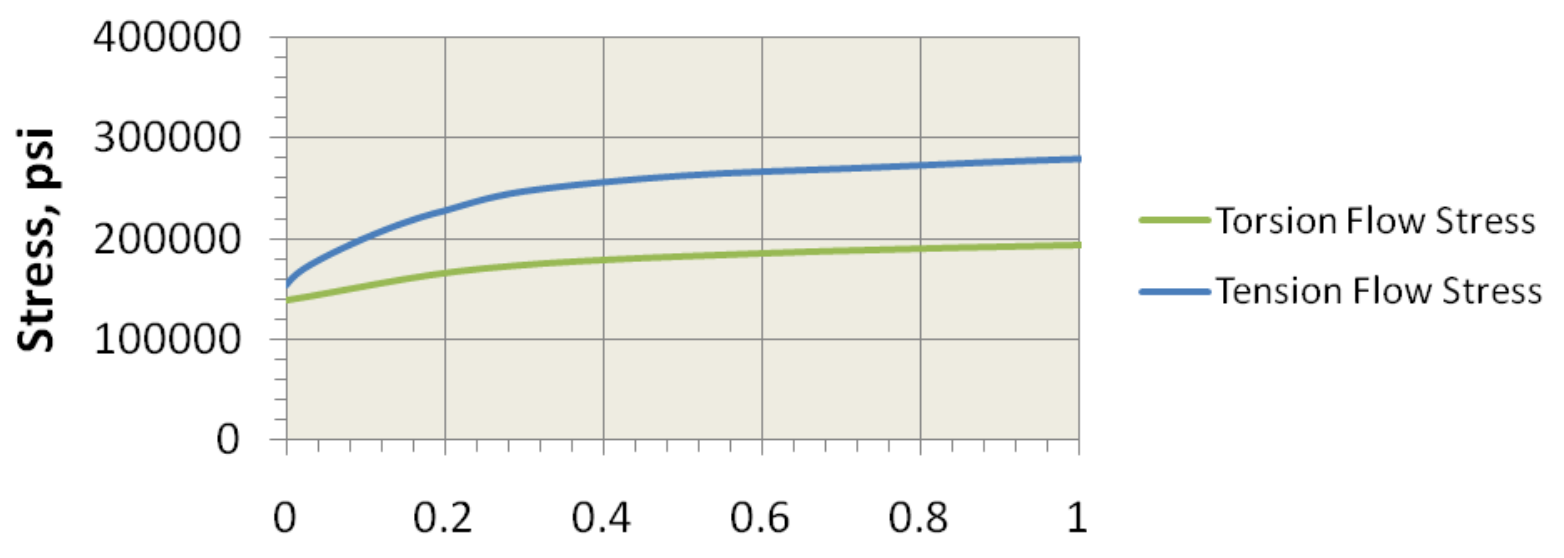

Plastic Strain

Figure 4. Tensile vs. Shear Flow Stress Curves - Inconel 718

Research [3, 4] shows that classical $\mathrm{J}_{2}$ (Mises) plasticity theory may not be applicable to flowforming because of the complex stress states. It is proposed that a materials yield (flow) behavior is a function of equivalent stress, triaxiality, and the third invariant of the deviatoric stress as shown below. It is hypothesized that the dependence relies less on traixiality than on deviatoric stress state.

$\sigma_{y \text { teld }}=\bar{\sigma}\left(\bar{c}_{p}\right) f_{p}(\eta) f_{\theta}(\xi)$

In the limiting case of $f_{p}(1)=f_{p}(\xi)=1$, equation (1) reduces to classical $J_{2}$ theory. Because Abaqus $^{\text {TM }}$ does not yet support the proposed plasticity model, trials will have to be compared using a single flow stress curve. The results and how well they correlate to physical trials will dictate which curve is more applicable to flowforming.

\section{Damage Model Development}

The governing hypothesis of the Xue-Wierzbicki damage model $[5,6,7,8]$ is that:

$\Delta D=\frac{\Delta a_{y}}{a_{f}\left(\eta_{i}, h\right)}$

where $\Delta \mathrm{D}$ is the incremental damage accumulation, $\Delta \varepsilon_{\mathrm{p}}$ is the incremental plastic strain, and $s_{f}(\eta, s, \xi)$ is the strain at failure as a function of $\eta$, triaxial stress; $\dot{s}$, strain rate; and $\xi$, the deviatoric stress state. It was assumed that strain rate and deviatoric stress were negligible for 
this problem. The possible effects of neglecting the deviatoric stress state will be discussed below.

When the material is fully damaged, $\mathrm{D}=1$, the material's stiffness will degrade by a factor $S_{\text {deg }}$, which exponentially increases with plastic displacement.

In order to populate the damage model, a curve must be created relating strain to failure, $\varepsilon_{f}$, and triaxiality, $\eta$. Models and comparisons to several different specially designed test specimens were developed to determine the material's strain to failure over a range of stress states. This test and model methodology used by the NDCEE team was successful, demonstrating that it can be used to build an accurate material model to simulate the flowforming process in Abaqus ${ }^{\mathrm{TM}}$. Figure 5 shows a comparison of the FEA damage and failure propagation for the mixed shear (compression) specimen with a photo of the failed specimen.

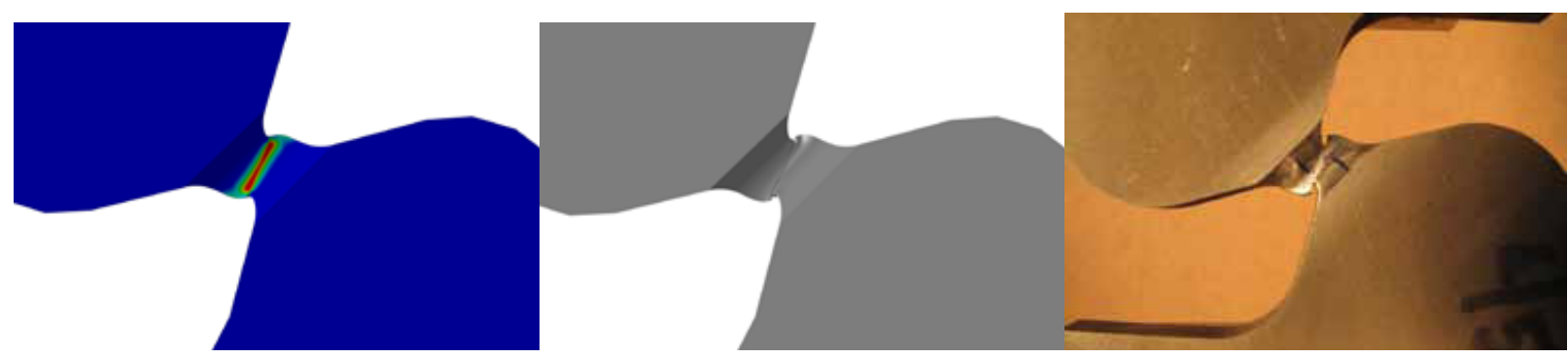

Figure 5. FEA and Physical Specimen Failure Comparison

Figure 6 shows the resulting damage model for Inconel 718 and notes the types of specimens used to develop the curve. This figure shows both a tensile and shear curve, which if the initial assumption of a minimal deviatoric stress influence were true, would not be necessary. However, further research [7, 9, 3, 4, 10] and analysis showed that the initial assumption of neglecting the effects of third invariant of the stress deviator on the ductile damage model may not have been entirely valid: there may be a large variance in ductility as a function of deviatoric state and slight differences in loading can have a very significant impact on overall ductility. Of the specimens used to develop the damage model, all are plane stress tests with exception of the notched and pure tensile specimen which were axisymmetric. There are currently a limited number of calibration tests with a constant triaxial and deviatoric stress state, which limits the extent to which the entire 3 dimensional fracture locus can be populated. Further research needs to be done to design new test specimens and procedures to populate this region. 


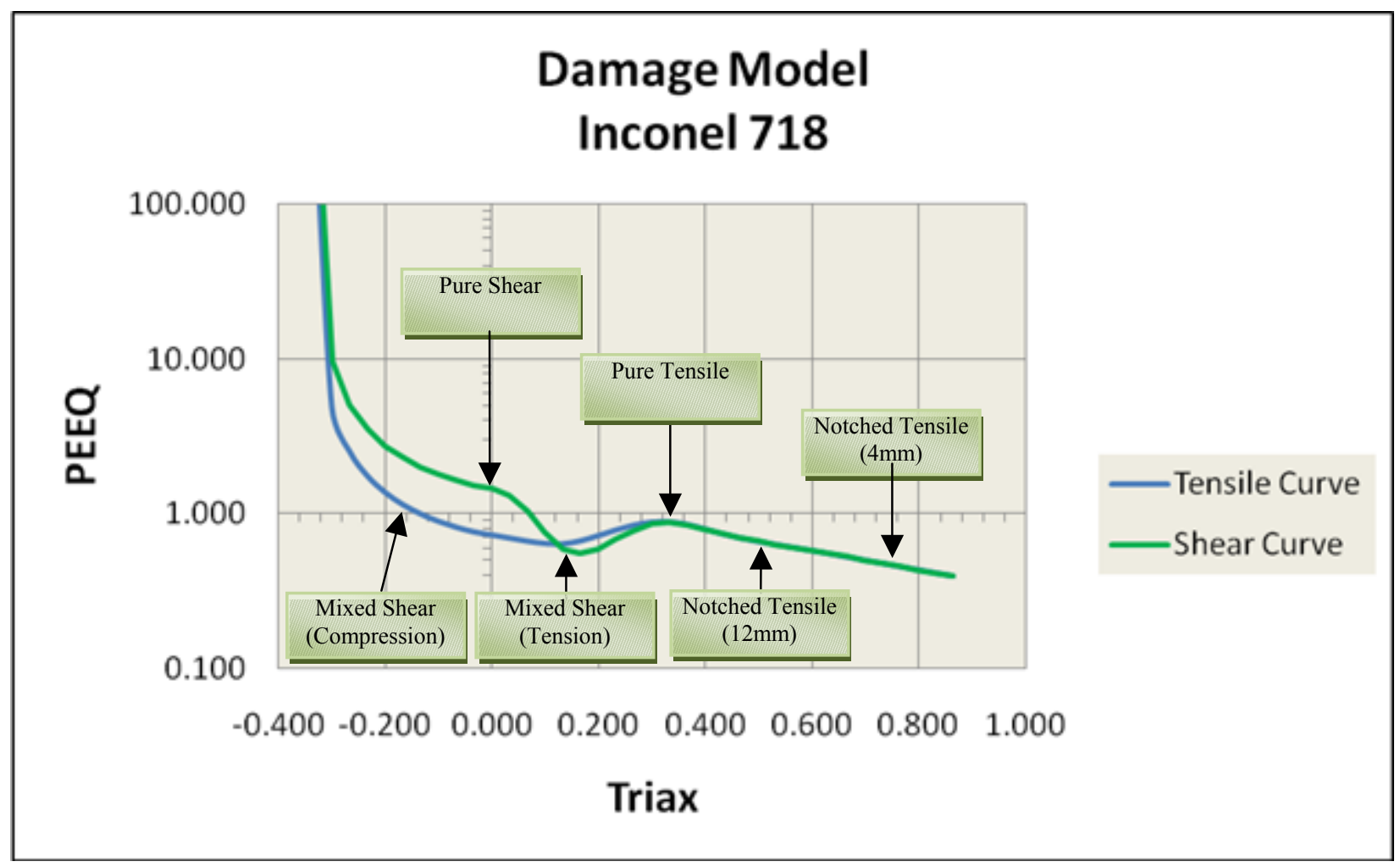

Figure 6. Inconel 718 Ductile Damage Model

\section{Process Model Development}

The flowforming process model incorporates the material failure model with a physical representation of the flowforming mandrel, preform, and rollers. The process model calculates the stresses, strains, and deformations the material will be subject to during flowforming. The process model can be used to assess the effects of changing parameters of the flowforming process on the material behavior. These parameters include reduction, feed rate, roller geometry, preform geometry, and others. Figure 8 shows the process model for reverse flowforming.

A successful flowforming operation was performed on an Inconel 718 preform. The run was performed as a continuous four pass reverse flow operation with no intermediate heat treatment. Ideally, the final predicted damage value would be below 1.0 when modeling a known successful trial. Ductile damage values for the four passes were predicted at 0.58, 1.3, 2.2, and 2.7. Therefore, at this time, due to software implementation and technological limitations, the numerical process model is not an absolute predictor of ductile damage. However, the current process and ductile damage models as implemented in Abaqus ${ }^{\mathrm{TM}}$ will only establish trends which allows for relative optimization.

The correlation between the experimental and predicted wall thickness after each pass is especially important for producing near net shape products. Final wall thickness is primarily a function of three parameters: percent reduction, elastic material recovery, and machine compliance. Percent reduction directly drives the wall thickness toward the target while elastic material recovery and machine compliance cause undesired deviation. 


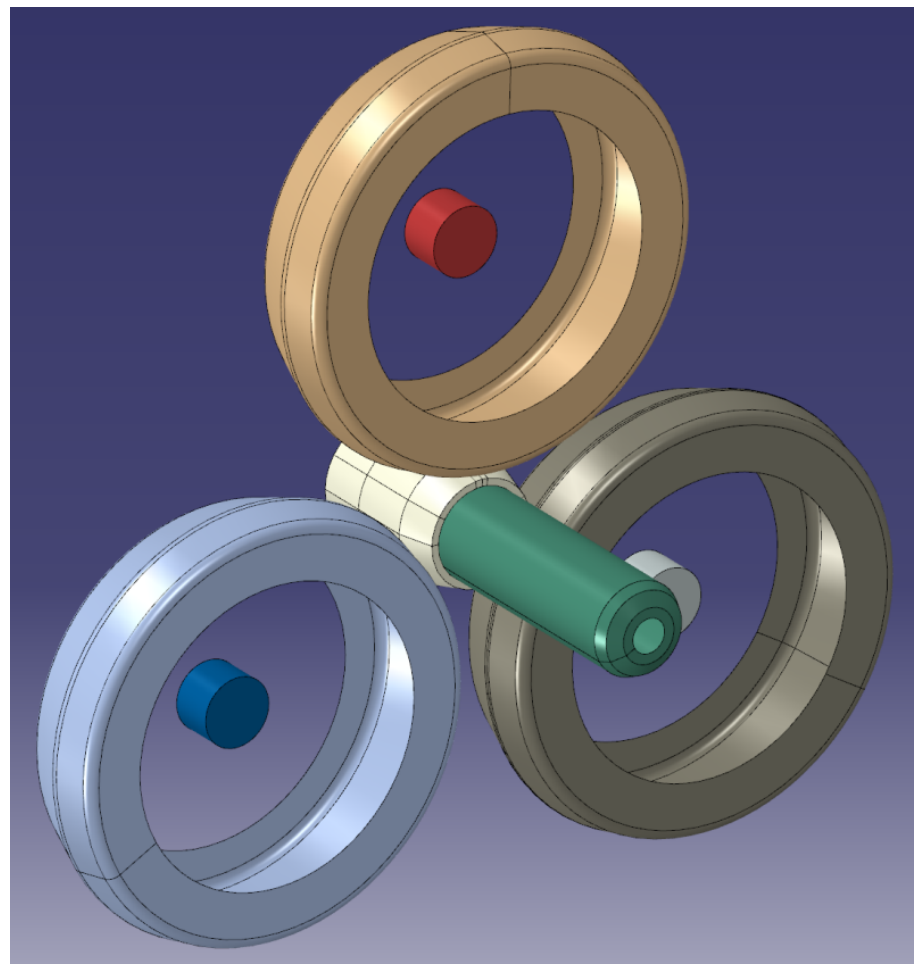

Figure 8. Reverse Forming Geometry and Assembly

The simulation did predict wall thicknesses approximately $10 \%$ lower than what were produced in the baseline trial. This difference is largely because the process model does not include machine compliance as it uses rigid connections. Machine compliance, if quantified into a stiffness per roller, could be added to the numerical model via elasticity (linear or nonlinear) in the roller translator joints in order to improve the accuracy of the simulation.

A six variable design of experiment was created which offers guidance to input parameter optimization with respect to process model response, i.e., material plasticity, part damage, and roller loads. Analyses showed that increased feed rate and reduced attack angle decreased overall damage in the part, especially OD damage, while increasing ID damage and roller loads. Similarly, staggered rollers reduced roller loads and overall part damage, specifically on the ID, at the expense of a slight increase in OD damage.

\section{Conclusions}

The material characterization and numerical methods used to construct this process model are at the forefront of technology. Research and development efforts still continue to understand the complex relationships between material microstructure, plasticity, triaxial stress states, and deviatoric stress states and how they contribute to progressive damage and ultimate failure thus many of the recent advancements have not yet been implemented into the software code. Therefore, additional use and development of the material and process models to improve correlation to the physical response is required. 


\section{References}

(1) 1. Atlas of Time-temperature Diagrams for Non-Ferrous Alloys, ASM International, Metals Park, OH, 1991, pp.196 - 220.

(2) 2. A. K. Lis, G. I. Garcia, A. J. DeArdo, "The Effect of Homogenization Treatment and Cooling Rate on the Transformation Characteristics of Alloy 718," International Symposium on Superalloys, September, 1992.

(3) 3. Yuanli Bai, "Effect of Loading History on Necking and Fracture," Ph.D Thesis, Massachusetts Institute of Technology, February 2008.

(4) 4. Liang Xue, "Ductile Fracture Modeling - Theory, Experimental Investigation and Numerical Verification," Ph.D Thesis, Massachusetts Institute of Technology, June 2007.

(5) 5. Tomasz Wierzbicki, Yingbin Bao, Young-Woong Lee, and Yuanli Bai, "Calibration and Evaluation of Seven Fracture Models," International Journal of Mechanical Sciences, Volume 47, Issues 4-5, April-May 2005, Pages 719-743

(6) 6. Yingbin Bao and Tomasz Wierzbicki, "On the Cut-off Value of Negative Triaxiality for Fracture," Engineering Fracture Mechanics, Volume 72, Issue 7, May 2005, Pages 1049-1069

(7) 7. Tomasz Wierzbicki and Liang Xue, "On the Effect of the Third Invariant of the Stress Deviator on Ductile Fracture," Impact \& Crashworthiness Lab, Massachusetts Institute of Technology, Report No: 136, October 2005

(8) 8. Yingbin Bao and Tomasz Wierzbicki, "On Fracture Locus in the Equivalent Strain and Stress Triaxiality Space," International Journal of Mechanical Sciences, Volume 46, Issue 1, January 2004, Pages 81-98

(9) 9. Liang Xue, "Ductile Fracture Modeling - Theory, Experimental Investigation and Numerical Verification," Massachusetts Institute of Technology, February 15, 2007

(10) 10. Tomasz Wierzbicki, "Fracture of AHSS Sheets and Status of the AHSS Consortium at MIT (Addendum to the Research Proposal on "Fracture of Advanced High Strength Steels")," Impact \& Crashworthiness Lab, Massachusetts Institute of Technology, January 2007 